\title{
Cardiac Alterations on 3T MRI in Young Adults With Sedentary Lifestyle-Related Risk Factors
}

\author{
Gert J. H. Snel ${ }^{1 *}$, Maaike van den Boomen ${ }^{1,2,3}$, Katia Hurtado-Ortiz ${ }^{4}$, \\ Riemer H. J. A. Slart ${ }^{5,6}$, Vincent M. van Deursen ${ }^{7}$, Christopher T. Nguyen ${ }^{2,3}$, \\ David E. Sosnovik ${ }^{2,3,8}$, Rudi A. J. O. Dierckx ${ }^{5}$, Birgitta K. Velthuis ${ }^{9}$, Ronald J. H. Borra ${ }^{1,5}$ \\ and Niek H. J. Prakken ${ }^{1}$
}

\section{OPEN ACCESS}

Edited by:

Sebastian Kelle,

Deutsches Herzzentrum

Berlin, Germany

Reviewed by:

Andrew Remppis,

Heart and Vascular Center Bad

Bevensen, Germany

Filippo Cademartiri,

Gabriele Monasterio Tuscany

Foundation (CNR), Italy

Sorin Giusca,

GRN Klinik Weinheim, Germany

Undine Witt

German Heart Center Berlin, Germany

*Correspondence:

Gert J. H. Snel

g.j.h.sne/@umcg.nl

Specialty section

This article was submitted to

Cardiovascular Imaging,

a section of the journal

Frontiers in Cardiovascular Medicine

Received: 21 December 2021

Accepted: 18 January 2022

Published: 22 February 2022

Citation:

Snel GJH, van den Boomen M.

Hurtado-Ortiz K, Slart RHJA, van

Deursen VM, Nguyen CT,

Sosnovik DE, Dierckx RAJO,

Velthuis BK, Borra RJH and

Prakken NHJ (2022) Cardiac

Alterations on $3 T$ MRI in Young Adults

With Sedentary Lifestyle-Related Risk

Factors.

Front. Cardiovasc. Med. 9:840790.

doi: $10.3389 / f c v m .2022 .840790$

\begin{abstract}
${ }^{1}$ Department of Radiology, Medical Imaging Center, University Medical Center Groningen, University of Groningen, Groningen, Netherlands, ${ }^{2}$ Department of Radiology, Athinoula A. Martinos Center for Biomedical Imaging, Massachusetts General Hospital and Harvard Medical School, Boston, MA, United States, ${ }^{3}$ Cardiovascular Research Center,

Massachusetts General Hospital and Harvard Medical School, Boston, MA, United States, ${ }^{4}$ Faculty of Medicine, National Autonomous University of Mexico (UNAM), Ciudad Universitaria, Mexico City, Mexico, ${ }^{5}$ Department of Nuclear Medicine and Molecular Imaging, Medical Imaging Center, University Medical Center Groningen, University of Groningen, Groningen, Netherlands, ${ }^{6}$ Department of Biomedical Photonic Imaging, Faculty of Science and Technology, University of Twente, Enschede, Netherlands, ${ }^{7}$ Department of Cardiology, University Medical Center Groningen, University of Groningen, Groningen, Netherlands, ${ }^{8}$ Harvard-MIT Division of Health Sciences and Technology, Cambridge, MA, United States, ${ }^{9}$ Department of Radiology, University Medical Center Utrecht, University of Utrecht, Utrecht, Netherlands
\end{abstract}

Background: Young adult populations with the sedentary lifestyle-related risk factors overweight, hypertension, and type 2 diabetes (T2D) are growing, and associated cardiac alterations could overlap early findings in non-ischemic cardiomyopathy on cardiovascular MRI. We aimed to investigate cardiac morphology, function, and tissue characteristics for these cardiovascular risk factors.

Methods: Non-athletic non-smoking asymptomatic adults aged 18-45 years were prospectively recruited and underwent 3Tesla cardiac MRI. Multivariate linear regression was performed to investigate independent associations of risk factor-related parameters with cardiac MRI values.

Results: We included 311 adults (age, $32 \pm 7$ years; men, 49\%). Of them, 220 subjects had one or multiple risk factors, while 91 subjects were free of risk factors. For overweight, increased body mass index (per $S D=5.3 \mathrm{~kg} / \mathrm{m}^{2}$ ) was associated with increased left ventricular (LV) mass $(+7.3 \mathrm{~g})$, biventricular higher end-diastolic (LV, $+8.6 \mathrm{ml})$, and stroke volumes $(\mathrm{SV} ;+5.0 \mathrm{ml})$, higher native $T_{1}(+7.3 \mathrm{~ms})$, and lower extracellular volume (ECV, $-0.38 \%)$, whereas the higher waist-hip ratio was associated with lower biventricular volumes. Regarding hypertension, increased systolic blood pressure (per SD $=14 \mathrm{mmHg}$ ) was associated with increased LV mass $(+6.9 \mathrm{~g})$, higher LV ejection fraction (EF; +1.0\%), and lower ECV (-0.48\%), whereas increased diastolic blood pressure was associated with lower LV EF. In T2D, increased HbA1c (per SD = $9.0 \mathrm{mmol} / \mathrm{mol}$ ) was associated with increased LV mass (+2.2 g), higher right ventricular end-diastolic volume $(+3.2 \mathrm{ml})$, and higher ECV $(+0.27 \%)$. Increased heart rate was linked with decreased LV mass, lower biventricular volumes, and lower $T_{2}$ values. 
Conclusions: Young asymptomatic adults with overweight, hypertension, and T2D show subclinical alterations in cardiac morphology, function, and tissue characteristics. These alterations should be considered in cardiac MRI-based clinical decision making.

Keywords: young adults, cardiovascular magnetic resonance imaging, overweight, hypertension, type 2 diabetes, cardiac function, myocardial tissue characterization

\section{INTRODUCTION}

Increased western diet consumption combined with a sedentary lifestyle drives the global prevalence of being overweight and having obesity (1). While previously mostly seen in aging populations, today younger populations are more frequently affected (2). Consequently, the onset of both hypertension and type 2 diabetes (T2D) is also shifting to younger age groups $(3,4)$, subsequently increasing cardiovascular disease prevalence (5).

Non-ischemic cardiomyopathy is the most frequent cause of sudden cardiac death in the young, whereas the prevalence of ischemic cardiomyopathy increases with age (6). Young adults with non-specific cardiovascular symptoms are therefore often referred for MRI to rule out non-ischemic cardiomyopathy (7). Pathological cardiac MRI findings include left ventricular hypertrophy (LVH), chamber dilatation, and decreased ejection fraction (EF) (8). Early changes in cardiomyopathy are subtle and could overlap comparable alterations in overweight, hypertension, and T2D (9). Large cohort studies in mature adults (mean age, 55-62 years old) show overweight to be independently associated with increased LV mass and cardiac volumes, hypertension with increased LV mass, and T2D with smaller volumes (10-13). As included populations were asymptomatic and free of cardiovascular disease, the aforementioned alterations can be considered risk factor-related cardiac adaptation. To our best knowledge, the impact of these risk factors in younger adults has not been demonstrated yet.

Quantitative myocardial tissue characterization has an increasingly complementary role in the diagnosis of nonischemic cardiomyopathies (14). For example, cardiomyopathies featuring myocardial fibrosis or edema show respectively prolonged native $T_{1}$ and $T_{2}$ mapping values $(15,16)$, and in some cases, also increased extracellular volume (ECV) (17). In high-risk populations, these mapping values could be different, which should be taken into account to avoid misdiagnosis. In athletes, for example, native $T_{1}$ and $T_{2}$ mapping and ECV have already been described to be discriminative for the athlete's heart and cardiomyopathy $(14,18)$. Previous studies in mature hypertensive populations have reported higher native $\mathrm{T}_{1}$ values and ECV in presence of LVH (19), however, as these increases were smaller than seen in patients with hypertrophic cardiomyopathy (HCM), these markers may serve as potential

\footnotetext{
Abbreviations: BMI, body mass index; DBP, diastolic blood pressure; ECV, extracellular volume; EDV, end-diastolic volume; EF, ejection fraction; HbAlc, hemoglobin Alc; HCM, hypertrophic cardiomyopathy; LV, left ventricle; LVH, left ventricular hypertrophy; MRI, magnetic resonance imaging; RV, right ventricle; SBP, systolic blood pressure; SD, standard deviation; SSFP, steady-state free precession; SV, stroke volume; T2D, type 2 diabetes; HR, heart rate.
}

discriminators (20). In mature patients with T2D, ECV was mainly higher without clear changes in native $\mathrm{T}_{1}$ values (21). In both younger and older adult obese populations, no differences were reported in native $T_{1}$ values and $\operatorname{ECV}(22,23) . T_{2}$ mapping values have only been reported in mature hypertensive and T2D subjects, both show higher values than in healthy controls $(24,25)$.

The aim was to investigate the impact and possible combined effects of overweight, hypertension, and T2D on cardiac morphology, function, and tissue characteristics in an asymptomatic young adult population.

\section{METHODS}

\section{Study Population}

This prospective cross-sectional single center study was approved by the local Medical Ethics Review Committee, in accordance with the declaration of Helsinki, and all subjects signed informed consent prior to participation. We recruited individuals aged 18-45 years old with at least one cardiovascular risk factor: overweight, hypertension, or T2D. Overweight was defined as a body mass index $(\mathrm{BMI}) \geq 25 \mathrm{~kg} / \mathrm{m}^{2}$, hypertension as under pharmacological treatment or three consecutive blood pressure measurements $\geq 140 / 90 \mathrm{mmHg}$, and $\mathrm{T} 2 \mathrm{D}$ as under pharmacological treatment or hemoglobin A1c (HbAlc) $\geq$ $48 \mathrm{mmol} / \mathrm{mol}$. Healthy individuals without cardiovascular risk factors were additionally included as controls. All subjects were recruited using public advertisements and scanned between August 2017 and July 2019 strictly for study purposes without a clinical indication. Exclusion criteria for participation were cardiac history, cardiac symptoms, and cardiovascular comorbidities. Current smoking and exercising ( $>3 \mathrm{~h} / \mathrm{wk}$ ) were also exclusion criteria to minimize the impact of other covariates on the heart $(10,26)$. Body weight, blood pressure, and hip and waist circumference were measured. Body weight was measured while wearing only MRI-safe clothes and rounded down to correct for this. Blood pressure was measured in a sitting position after resting for at least $5 \mathrm{~min}$ (27). Blood samples were obtained shortly before the MRI examination to assess HbAlc, glucose, and hematocrit.

\section{MRI Data Acquisition}

All study participants underwent cardiac MRI on a 3Tesla scanner (MAGNETOM Prisma, Siemens Healthineers, Erlangen, Germany) equipped with a 60-channel phased-array coil. All examinations were performed by experienced operators using breath-holds and electrocardiographic gating.

Steady-state free precession (SSFP) sequences were used to acquire short-axis cines covering the entire heart with a slice 
thickness of $6 \mathrm{~mm}$, an interslice gap of $4 \mathrm{~mm}$, and 25 phases per cardiac cycle (28). Long-axis cines were acquired with the same settings and included a single slice in 4-chamber view, and in 2-chamber view and outflow tract of the left and right ventricle. Detailed imaging parameters are provided in Supplementary Table S1.

$\mathrm{T}_{1}$ mapping was performed using a Modified Look-Locker Inversion Recovery 5(3)3 sequence on a basal, midventricular, and apical $8 \mathrm{~mm}$ short-axis slice (14). Measurements were performed before and at least $10 \mathrm{~min}$ after administration of $0.2 \mathrm{mmol} / \mathrm{kg}$ Gadoteric acid (Dotarem, Guerbet, Paris, France) (28). $\mathrm{T}_{2}$ mapping was performed on the same three shortaxis slices before contrast administration using a $\mathrm{T}_{2}$-prepared SSFP sequence with different $\mathrm{T}_{2}$-preparation times $(0,30$, and $55 \mathrm{~ms}$ ) (14).

\section{Image Analysis}

All image post-processing was performed on cvi42 (Circle Cardiovascular Imaging, Calgary, Canada). Cardiac function analysis was performed by contour-tracing the short-axis cines according to previously published instructions (29).

Native and post-contrast $\mathrm{T}_{1}$ maps were generated for each short-axis slice using the motion-corrected images with different inversion times. $\mathrm{T}_{2}$ maps were generated using motion-corrected images with different echo times. All generated maps were manually segmented and reported according to the 16-segment American Heart Association model (14). Apical segments were excluded from the global analysis because of the increased risk of artifacts (30).

\section{Statistical Analysis}

Statistical analysis was performed using SPSS (version 24.0, IBM Corp., Armonk, NY, USA). Continuous variables were presented as mean $\pm \mathrm{SD}$.

Multivariate linear regression models were created for LV mass, LV and right ventricular (RV) end-diastolic volume (EDV), stroke volume (SV), EF, native $\mathrm{T}_{1}, \mathrm{ECV}$, and $\mathrm{T}_{2}$. As $\mathrm{LV}$ and RV SV are similar in subjects without valvular leakage, their corresponding models are also similar (10), and therefore we did not report the model of the RV SV. Each model was initially fitted using the non-modifiable-independent clinical variables age, gender, and height. Height was used to scale for body size instead of body surface area to prevent from underestimating the effect of overweight with BMI $(10,11)$. The initial models were then expanded by adding the independent clinical variables related to cardiovascular risk factors, including BMI, waist-hip ratio, systolic (SBP) and diastolic blood pressure (DBP), and HbA1c. Heart rate (HR) was also included in the full model as it is often increased in high-risk populations and also is an additional risk factor for cardiovascular disease (31). Weight was not included as an independent variable, because of the correlation with height. In the full models, the $ß$-coefficient represents the change in a dependent variable given a change of one SD in an independent variable, with SD calculated based on the entire study population. Values of $p$ below 0.05 were considered statistically significant.

The percentage of variation in each cardiac MRI outcome that was explained by the full model was indicated with the coefficient of determination, i.e., the $\mathrm{R}^{2}$ value (32). Subsequently, the $\mathrm{R}^{2}$ value of the full model was reduced with the $\mathrm{R}^{2}$ value of the initial model to indicate the percentage of variation that was explained by cardiovascular risk factors in addition to the non-modifiable variables. For each significant independent variable in the full model, the semi-partial correlation coefficient was squared to calculate the unique variance explained by that variable (32). The presence of multicollinearity between independent variables was assessed using Pearson correlation $(>0.8)$ and the variance inflation factor (>5) (33).

\section{RESULTS}

\section{Study Population Characteristics}

Three hundred and twenty-two subjects were recruited for participation. Eleven subjects were excluded from analysis as the cardiac MRI examination was unsuccessful due to either claustrophobia or scanner bore size limitations. Three hundred and eleven subjects (age, $32 \pm 7$ years; men, 49\%) were included (Table 1). Of them, 91 subjects were free of risk factors (i.e., controls), and 220 subjects had at least one risk factor. The presence and overlap of cardiovascular risk factors are summarized in Table $\mathbf{1}$ and visualized in Figure $\mathbf{1}$. All MRI scans were screened for hemodynamically significant valvular abnormalities on all acquired long-axis cines and also for the presence of late gadolinium enhancement, none were observed. Subjects with either two or three risk factors showed higher HRs than subjects without or with one risk factor ( $80 \pm 13$ vs. $69 \pm 11 \mathrm{bpm}, p<0.01$ ). Additional cardiac MRI morphology, function, and tissue characteristics per gender are provided in Supplementary Table S2, and genderspecific per risk factor in Supplementary Tables S3, S4. The univariate analyses of independent clinical variables on cardiac MRI values are reported in Supplementary Tables S5-S14. Multicollinearity between independent variables was not demonstrated (Supplementary Tables S15, S16).

\section{Morphology and Function}

The multivariate linear regression models for cardiac morphology and function are reported in Table 2. The contribution of independent variables to the variation in cardiac MRI outcomes is visualized in Figure 2 and Supplementary Figure S1. Higher LV mass was independently associated with increasing BMI $\left(\beta=7.3 \mathrm{~g}\right.$ per $\mathrm{SD}\left(5.3 \mathrm{~kg} / \mathrm{m}^{2}\right)$, $p<0.001)$, SBP $(\beta=6.9 \mathrm{~g}$ per SD (14 mmHg), $p<0.001)$, and $\mathrm{HbAlc}(\beta=2.2 \mathrm{~g}$ per SD $(9.0 \mathrm{mmol} / \mathrm{mol}), p<0.05)$. LV mass was lower with increasing $\mathrm{HR}(\beta=-4.5 \mathrm{~g}$ per SD (11 bpm), $p<0.001$ ), while waist-hip ratio and DBP had no impact on LV mass. Among all ventricular parameters, the full model explained the most variation in LV mass of which $18 \%$ was added by risk factors.

Higher LV mass/volume ratio was associated with increasing BMI $(~(=0.015 \mathrm{~g} / \mathrm{ml}$ per $\mathrm{SD}, p<0.05)$, waist-hip ratio $(\beta=0.019$ $\mathrm{g} / \mathrm{ml}$ per SD (0.078), $p<0.05)$, SBP $(\beta=0.028 \mathrm{~g} / \mathrm{ml}$ per SD, $p<$ $0.001)$, and $\mathrm{HR}(\beta=0.018 \mathrm{~g} / \mathrm{ml}$ per $\mathrm{SD}, p<0.01)$. Associations with DBP $(p=0.06)$ and HbAlc $(p=0.08)$ were not significant. Compared to other ventricular parameters, cardiovascular risk 
TABLE 1 | Study population characteristics.

\begin{tabular}{|c|c|c|c|}
\hline & & Males $(n=151)$ & Females $(n=160)$ \\
\hline Age (years) & & $32.6 \pm 6.3$ & $31.5 \pm 7.1$ \\
\hline Height (cm) & & $184 \pm 7$ & $171 \pm 6$ \\
\hline Weight (kg) & & $91 \pm 17$ & $82 \pm 17$ \\
\hline Body mass index $\left(\mathrm{kg} / \mathrm{m}^{2}\right)$ & & $26.9 \pm 4.9$ & $28.0 \pm 5.7$ \\
\hline Body surface area $\left(\mathrm{m}^{2}\right)$ & & $2.13 \pm 0.20$ & $1.94 \pm 0.19$ \\
\hline Lean body mass (kg) & & $64 \pm 9$ & $47 \pm 6$ \\
\hline Waist size $(\mathrm{cm})$ & & $98 \pm 13$ & $95 \pm 15$ \\
\hline Hip size (cm) & & $102 \pm 9$ & $108 \pm 12$ \\
\hline Waist-hip ratio & & $0.95 \pm 0.07$ & $0.89 \pm 0.07$ \\
\hline Systolic blood pressure (mmHg) & & $130 \pm 13$ & $125 \pm 15$ \\
\hline Diastolic blood pressure (mmHg) & & $84 \pm 9$ & $82 \pm 10$ \\
\hline Hemoglobin A1c (mmol/mol) & & $35.1 \pm 9.1$ & $34.7 \pm 8.9$ \\
\hline Glucose (mmol/L) & & $5.9 \pm 1.8$ & $5.7 \pm 1.6$ \\
\hline Haematocrit (\%) & & $44.1 \pm 2.4$ & $39.5 \pm 2.5$ \\
\hline Heart rate (bpm) & & $69 \pm 11$ & $70 \pm 11$ \\
\hline \multirow[t]{6}{*}{ Risk factors* } & Overweight & $91(60 \%)$ & 104 (65\%) \\
\hline & Hypertension with medication & $21(14 \%)$ & $26(16 \%)$ \\
\hline & Hypertension without medication & $18(12 \%)$ & $13(8 \%)$ \\
\hline & Type 2 diabetes with medication & $10(7 \%)$ & $11(7 \%)$ \\
\hline & Type 2 diabetes without medication & $1(1 \%)$ & $0(0 \%)$ \\
\hline & None (controls) & 44 (29\%) & 47 (29\%) \\
\hline
\end{tabular}

Data presented as mean $\pm S D$ or $n(\%)$. *Overlap of risk factors is visualized in Figure 1.

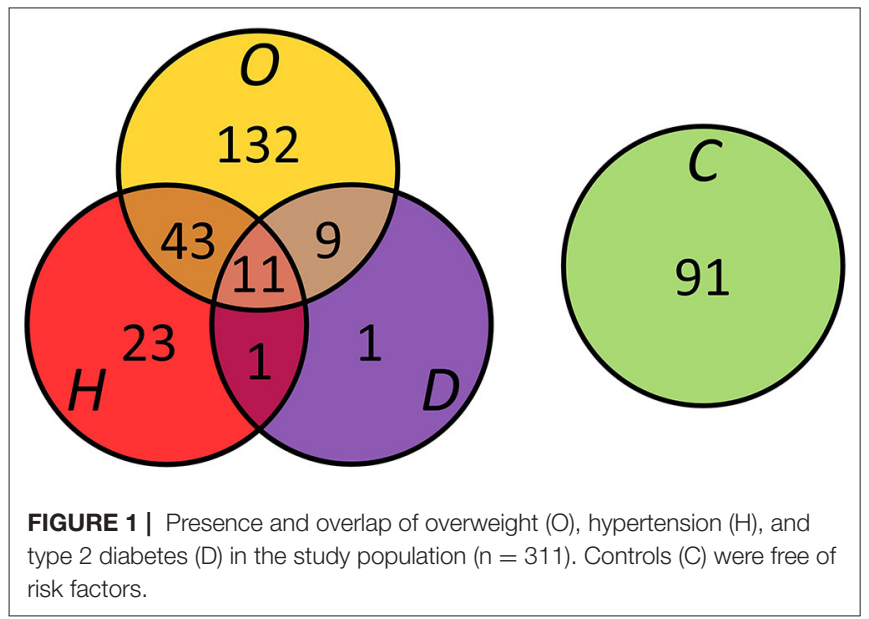

factors explained the most variation in the LV mass/volume ratio $\left(\mathrm{R}^{2}=24 \%\right)$.

Higher LV EDV was associated with increasing BMI $(ß=$ $8.6 \mathrm{ml}$ per SD, $p<0.001)$. LV EDV was lower with increasing waist-hip ratio $(\beta=-7.5 \mathrm{ml}$ per $\mathrm{SD}, p<0.001)$, and $\mathrm{HR}(\beta$ $=-12.2 \mathrm{ml}$ per SD, $p<0.001)$. Furthermore, the association between LV EDV and SBP was not significant $(p=0.06)$, while DBP and HbA1c also had no impact.

Higher LV SV was associated with increasing $B M I(B=5.0 \mathrm{ml}$ per SD, $p<0.001)$ and SBP $(\beta=3.7 \mathrm{ml}$ per SD, $p<0.01)$. LV SV was lower with increasing waist-hip ratio $(\beta=-4.0 \mathrm{ml}$ per
$\mathrm{SD}, p<0.01)$, DBP ( $\beta=-3.6 \mathrm{ml}$ per SD (10 mmHg), $p<0.05)$, and $\mathrm{HR}(\beta=-7.1 \mathrm{ml}$ per $\mathrm{SD}, p<0.001)$. HbA1c had no impact on LV SV. The LV EF was only associated with SBP $(B=1.0 \%$ per SD, $p<0.05)$ and DBP $(B=-1.1 \%$ per SD, $p<0.05)$. The variation explained in LV EF by the full model $\left(\mathrm{R}^{2}=5 \%\right)$ was the lowest among all ventricular parameters.

\section{RV Morphology and Function}

Similar to the LV, the RV EDV was higher with increasing BMI ( $B$ $=9.9 \mathrm{ml}$ per $\mathrm{SD}, p<0.001)$ and lower with increasing waist-hip ratio $(B=-7.4 \mathrm{ml}$ per $\mathrm{SD}, p<0.001)$ and $\mathrm{HR}(\beta=-15 \mathrm{ml}$ per $\mathrm{SD}, p<0.001$; Table 2). Conversely to the LV, the RV EDV was also higher with increasing $\mathrm{SBP}(B=4.9 \mathrm{ml}$ per $\mathrm{SD}, p<0.05)$ and HbA1c $(B=3.2 \mathrm{ml}$ per $\mathrm{SD}, p<0.05)$, while RV EDV was lower with increasing $\mathrm{DBP}(\beta=-5.7 \mathrm{ml}$ per $\mathrm{SD}, p<0.05)$.

The RV EF was positively associated with $\mathrm{HR}(\beta=0.7 \%$ per $\mathrm{SD}, p<0.05)$ and negatively with $\mathrm{HbAlc}(\beta=-0.8 \%$ per $\mathrm{SD}$, $p<0.01)$. The other variables had no impact on the RV EF.

\section{Myocardial Tissue Characteristics}

The multivariate linear regression models for myocardial tissue characteristics are reported in Table 3. Higher native $T_{1}$ values were associated with increasing $\mathrm{BMI}(\beta=7.3 \mathrm{~ms}$ per $\mathrm{SD}, p<$ $0.01)$. Associations with SBP and DBP were not significant ( $p=$ $0.07)$, and all other variables had no impact. Only a little variation in native $T_{1}$ values was explained by the full model $\left(R^{2}=5 \%\right)$.

Higher ECV was associated with increasing HbA1c $(B=$ $0.27 \%$ per SD, $p<0.01)$. ECV was lower with increasing BMI $(ß=-0.38 \%$ per $\mathrm{SD}, p<0.01)$ and $\mathrm{SBP}(B=-0.48 \%$ per $\mathrm{SD}$, 
TABLE 2 | Multivariate linear regression models for cardiac morphology and function.

\begin{tabular}{|c|c|c|c|c|c|c|c|c|c|}
\hline & & & \multicolumn{5}{|c|}{ Left ventricle } & \multicolumn{2}{|c|}{ Right ventricle } \\
\hline & & & Mass & Mass/volume ratio $\left({ }^{*} 100\right)$ & End-diastolic volume & Stroke volume & Ejection fraction & End-diastolic volume & Ejection fraction \\
\hline \multicolumn{2}{|c|}{ Variable } & Per SD & Change (g) & Change (g/ml) & Change (ml) & Change (ml) & Change (\%) & Change (ml) & Change (\%) \\
\hline \multirow{3}{*}{$\begin{array}{l}\text { Non- } \\
\text { modifiable }\end{array}$} & Age & 6.8 years & $-2.3(-4.1,-0.6)^{\dagger}$ & $-0.1(-1.3,1.1)$ & $-3.0(-5.8,-0.1)^{\star}$ & $-0.6(-2.5,1.4)$ & $0.7(0.2,1.3)^{\star}$ & $-4.6(-7.8,-1.3)^{\dagger}$ & $0.8(0.3,1.4)^{\dagger}$ \\
\hline & Gender & Female & $-20(-25,-16)^{\ddagger}$ & $-9.7(-12.9,-6.6)^{\ddagger}$ & $-10.4(-17.9,-3.0)^{\dagger}$ & $-3.1(-8.2,1.9)$ & $1.9(0.3,3.4)^{*}$ & $-19(-28,-11)^{\ddagger}$ & $3.8(2.4,5.2)^{\ddagger}$ \\
\hline & Height & $9.0 \mathrm{~cm}$ & $8.4(6.3,10.5)^{\ddagger}$ & $-2.2(-3.7,-0.8)^{\dagger}$ & $19(16,23)^{\ddagger}$ & $11.3(8.9,13.6)^{\ddagger}$ & $-0.1(-0.7,0.6)$ & $22(18,25)^{\ddagger}$ & $0.2(-0.4,0.9)$ \\
\hline \multirow{6}{*}{$\begin{array}{l}\text { Risk } \\
\text { factors }\end{array}$} & $\mathrm{BMl}$ & $5.3 \mathrm{~kg} / \mathrm{m}^{2}$ & $7.3(5.4,9.0)^{\ddagger}$ & $1.5(0.2,2.8)^{\star}$ & $8.6(5.4,11.7)^{\ddagger}$ & $5.0(2.9,7.1)^{\ddagger}$ & $-0.0(-0.6,0.6)$ & $9.9(6.4,13.4)^{\ddagger}$ & $-0.2(-0.7,0.4)$ \\
\hline & WHR & 0.078 & $-0.8(-2.9,1.4)$ & $1.9(0.4,3.4)^{*}$ & $-7.5(-11.1,-3.8)^{\ddagger}$ & $-4.0(-6.5,-1.5)^{\dagger}$ & $0.2(-0.5,0.9)$ & $-7.5(-11.6,-3.4)^{\ddagger}$ & $-0.2(-0.8,0.5)$ \\
\hline & SBP & $14 \mathrm{mmHg}$ & $6.9(4.6,9.2)^{\ddagger}$ & $2.8(1.2,4.5)^{\ddagger}$ & $3.6(-0.2,7.5)$ & $3.7(1.1,6.4)^{\dagger}$ & $1.0(0.2,1.8)^{\star}$ & $4.9(0.6,9.3)^{\star}$ & $0.5(-0.2,1.3)$ \\
\hline & DBP & $10 \mathrm{mmHg}$ & $0.8(-1.6,3.2)$ & $1.7(-0.1,3.4)$ & $-3.0(-7.0,1.0)$ & $-3.6(-6.3,-0.8)^{\star}$ & $-1.1(-1.9,-0.2)^{\star}$ & $-5.7(-10.2,-1.1)^{\star}$ & $-0.2(-1.0,0.5)$ \\
\hline & $\mathrm{HbA1c}$ & $9.0 \mathrm{mmol} / \mathrm{mol}$ & $2.2(0.5,3.8)^{\star}$ & $1.0(-0.1,2.2)$ & $1.3(-1.4,4.0)$ & $0.0(-1.8,1.9)$ & $-0.5(-1.0,0.1)$ & $3.2(0.1,6.3)^{\star}$ & $-0.8(-1.3,-0.3)^{\dagger}$ \\
\hline & $\mathrm{HR}$ & 11 bpm & $-4.5(-6.1,-2.9)^{\ddagger}$ & $1.8(0.7,2.9)^{\dagger}$ & $-12.2(-14.9,-9.6)^{\ddagger}$ & $-7.1(-8.9,-5.3)^{\ddagger}$ & $0.1(-0.5,0.6)$ & $-15(-18,-12)^{\ddagger}$ & $0.7(0.1,1.2)^{\star}$ \\
\hline \multirow{4}{*}{$\begin{array}{l}\text { Variation } \\
\text { explained } \\
\text { by }\left(R^{2}\right)\end{array}$} & \multicolumn{2}{|c|}{ Non-modifiable variables } & $50.5 \%$ & $19.9 \%$ & $40.3 \%$ & $31.7 \%$ & $3.2 \%$ & $45.2 \%$ & $15.6 \%$ \\
\hline & \multicolumn{2}{|c|}{ Risk factors } & $18.4 \%$ & $23.5 \%$ & $16.1 \%$ & $14.9 \%$ & $1.4 \%$ & $16.1 \%$ & $3.8 \%$ \\
\hline & \multicolumn{2}{|c|}{ Full model } & $68.9 \%$ & $43.4 \%$ & $56.4 \%$ & $46.6 \%$ & $4.6 \%$ & $61.3 \%$ & $19.4 \%$ \\
\hline & \multicolumn{2}{|c|}{ Unknown variables } & $31.1 \%$ & $56.6 \%$ & $43.6 \%$ & $53.4 \%$ & $95.4 \%$ & $38.7 \%$ & $80.6 \%$ \\
\hline
\end{tabular}

Change in cardiac MRI value, noted as mean (95\% Cl), given a change of one standard deviation in the independent variable. Level of significance: ${ }^{*} p<0.05,{ }^{\dagger} p<0.01,{ }^{\ddagger} p<0.001 . S D$, standard deviation; $B M I$, body mass index; WHR, waist-hip ratio; SBP, systolic blood pressure; DBP, diastolic blood pressure; $H R$, heart rate. 


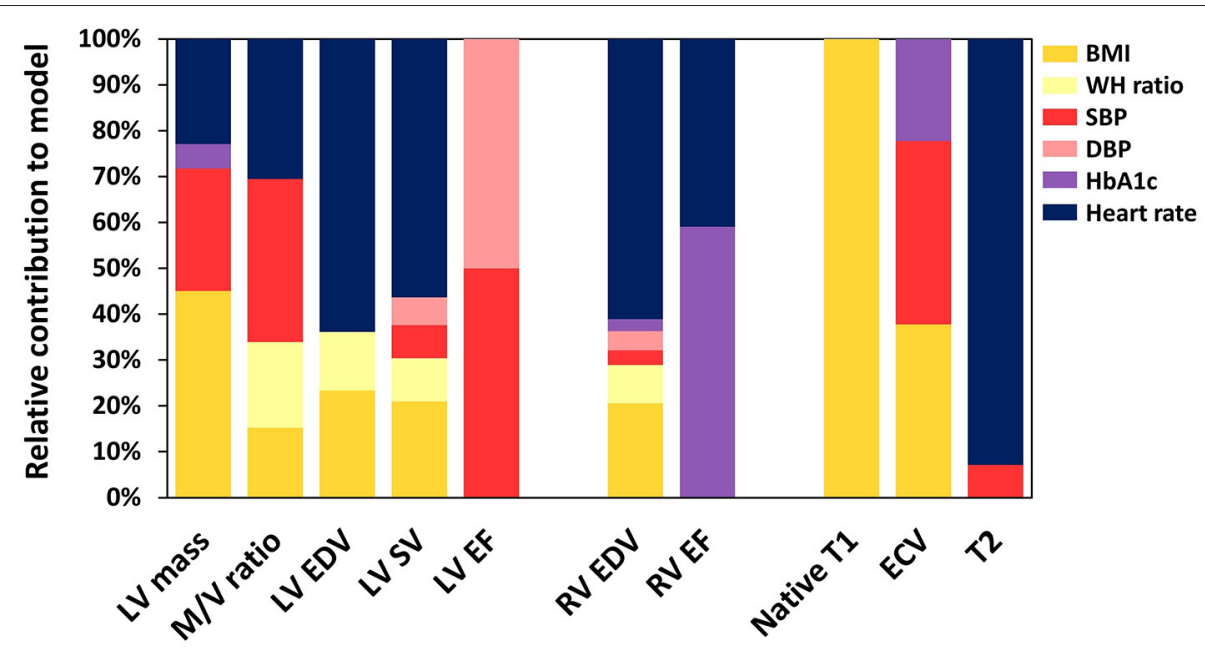

FIGURE 2 | The relative contribution of risk factors to the explanation of variation in cardiac MRI results. LV, left ventricle; M/V, mass/volume; EDV, end-diastolic volume; SV, stroke volume; EF, ejection fraction; RV, right ventricle; ECV, extracellular volume; BMI, body mass index; WH, waist96hip; SBP, systolic blood pressure; DBP, diastolic blood pressure.

$p<0.01)$. The full model explained $38 \%$ of the variation in $\mathrm{ECV}$, of which $7 \%$ was added by cardiovascular risk factors.

$\mathrm{T}_{2}$ values were lower with increasing SBP $(B=-0.39 \mathrm{~ms}$ per $\mathrm{SD}, p<0.01)$ and $\mathrm{HR}(\beta=-0.95 \mathrm{~ms}$ per SD, $p<0.001)$. All other variables had no impact on $\mathrm{T}_{2}$ values. Cardiovascular risk factors explained $33 \%$ of the variation in $\mathrm{T}_{2}$ values (full model $\left.\mathrm{R}^{2}=41 \%\right)$.

\section{DISCUSSION}

In this cross-sectional cardiac MRI study, we demonstrated that cardiovascular risk factors in an asymptomatic young adult cohort are associated with subclinical cardiac alterations. Substantial variation in LV mass, LV mass/volume ratio, cardiac volumes, $\mathrm{ECV}$, and $\mathrm{T}_{2}$ values was explained by independent clinical variables related to overweight, hypertension, and T2D. Variation in $\mathrm{EF}$ and native $\mathrm{T}_{1}$ values, however, was explained to a lesser extent.

With multivariate regression analysis, we showed that increased BMI, SBP, and HbAlc are independently associated with higher LV mass in young adults. The independent linkage of BMI and SBP on LV mass caused by respectively volume and pressure overload was in agreement with previous cardiac MRI findings in mature adult populations (age range, 41-85 years) (10-12) and an echocardiographic study in adolescents (mean age, $16 \pm 2$ years) that reported increasing LV mass with increasing blood pressure (34). The positive association between $\mathrm{HbAlc}$ and $\mathrm{LV}$ mass was in line with results in mature study cohorts $(11,35)$, but also with echocardiographic findings in young adults (mean age, $27 \pm 7$ years) (36). In the current study, risk factors explained less variation in LV mass compared to studies in mature populations (age range, 45-85 years) $(10,11)$. This difference might be age-related, as young adults are more likely to be exposed to these risk factors for a shorter period. Furthermore, in asymptomatic mature populations, increased LV mass is linked with heart failure events (37). This deleterious effect of increased LV mass could also occur in the growing young adult risk population, possibly worsening when conditions remain unchanged later in life.

Cardiac and SVs were significantly associated with BMI, waist-hip ratio, blood pressure, and $\mathrm{HR}$, while associations with $\mathrm{HbA1c}$ were less obvious. In previous studies, being overweight was linked to chamber dilatation with BMI as an independent predictor $(10-12,38)$. Although BMI is the gold standard to define overweight, it does not reflect on the actual body fat distribution which strongly correlates with cardiovascular risk, therefore we also included waist-hip ratio as an independent variable (39). As expected, increased BMI was associated with higher cardiac volumes, but surprisingly, a higher waist-hip ratio was associated with lower cardiac volumes and increased mass/volume ratio. These results confirm that especially central body fat deposition is associated with adverse concentric remodeling (40). We also found that cardiac volumes are lower with increased HR, confirming results in a previous study (38). Another study hypothesized that increased resting HR contributes to initial cardiac remodeling, requiring smaller cardiac volumes, and this possibly also applies to our young population (41). The opposite effect of SBP and DBP on end-diastolic and SVs was also in concordance with previous findings in mature populations (10-12). In this study, HbA1c only showed a positive association with RV volumes, while no impact on the LV was found which confirmed findings in a previous study in young T2D subjects (aged $32 \pm 7$ years) that only examined the LV (4). In mature populations, however, T2D was associated with smaller LV and RV volumes $(10,11)$, suggesting that the impact of T2D on 
TABLE 3 | Multivariate linear regression models for myocardial tissue characteristics.

\begin{tabular}{|c|c|c|c|c|c|}
\hline \multirow[b]{2}{*}{ Variable } & & \multirow[b]{2}{*}{ Per SD } & \multirow{2}{*}{$\begin{array}{c}\text { Native } \mathrm{T}_{1} \\
\text { Change (ms) }\end{array}$} & \multirow{2}{*}{$\begin{array}{c}\text { Extracellular volume } \\
\text { Change }(\%)\end{array}$} & \multirow{2}{*}{$\frac{\mathrm{T}_{2}}{\text { Change (ms) }}$} \\
\hline & & & & & \\
\hline \multirow[t]{3}{*}{ Non-modifiable } & Age & 6.8 years & $-2.5(-6.7,1.6)$ & $0.27(0.03,0.51)^{\dagger}$ & $0.08(-0.11,0.27)$ \\
\hline & Gender & Female & $9.0(-1.7,19.6)$ & $2.8(2.2,3.4)^{\ddagger}$ & $1.15(0.65,1.65)^{\ddagger}$ \\
\hline & Height & $9.0 \mathrm{~cm}$ & $7.6(2.7,12.6)^{\dagger}$ & $0.18(-0.11,0.46)$ & $-0.00(-0.23,0.23)$ \\
\hline \multirow[t]{6}{*}{ Risk factors } & $\mathrm{BMI}$ & $5.3 \mathrm{~kg} / \mathrm{m}^{2}$ & $7.3(2.9,11.7)^{\dagger}$ & $-0.38(-0.64,-0.12)^{\dagger}$ & $-0.16(-0.37,0.04)$ \\
\hline & WHR & 0.078 & $-3.9(-9.2,1.3)$ & $-0.04(-0.34,0.26)$ & $0.06(-0.19,0.30)$ \\
\hline & SBP & $14 \mathrm{mmHg}$ & $-5.2(-10.7,0.4)$ & $-0.48(-0.79,-0.16)^{\dagger}$ & $-0.39(-0.65,-0.13)$ \\
\hline & $\mathrm{DBP}$ & $10 \mathrm{mmHg}$ & $5.4(-0.4,11.2)$ & $-0.01(-0.35,0.32)$ & $0.03(-0.24,0.30)$ \\
\hline & $\mathrm{HbA1c}$ & $9.0 \mathrm{mmol} / \mathrm{mol}$ & $1.0(-2.9,5.0)$ & $0.27(0.04,0.49)^{\dagger}$ & $-0.12(-0.30,0.06)$ \\
\hline & $\mathrm{HR}$ & 11 bpm & $3.2(-0.6,7.1)$ & $-0.09(-0.31,0.12)$ & $-0.95(-1.13,-0.78)^{\prime}$ \\
\hline \multirow[t]{4}{*}{ Variation explained by $\left(R^{2}\right)$} & \multicolumn{2}{|c|}{ Non-modifiable variables } & $1.3 \%$ & $30.9 \%$ & $8.0 \%$ \\
\hline & \multicolumn{2}{|c|}{ Risk factors } & $4.1 \%$ & $7.0 \%$ & $33.3 \%$ \\
\hline & \multicolumn{2}{|c|}{ Full model } & $5.4 \%$ & $37.9 \%$ & $41.3 \%$ \\
\hline & \multicolumn{2}{|c|}{ Unknown variables } & $94.6 \%$ & $62.1 \%$ & $58.7 \%$ \\
\hline
\end{tabular}

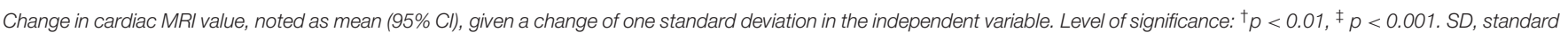
deviation; BMI, body mass index; WHR, waist-hip ratio; SBP, systolic blood pressure; DBP, diastolic blood pressure; HR, heart rate.

cardiac volumes could be age-related. As the aforementioned alterations in cardiac dimensions can overlap early findings in dilated cardiomyopathy, these need to be considered in imaging diagnostics (9).

The full models for LV and RV EF only explained respectively 5 and $20 \%$ of the existing variation. These low percentages, combined with the substantially higher explained variation for $\mathrm{RV}$ relative to $\mathrm{LV}$ function, confirmed regression models previously reported in mature populations (10-12). Similar to these studies, we showed that overweight-related variables had no impact on the EF (10-12). We also showed that SBP had a positive association, while DBP and $\mathrm{HbA1c}$ were negatively associated with EF. These results are in line with findings in older adult populations, suggesting that hypertension and T2D cause subclinical systolic changes irrespective of age.

To our best knowledge, this is the first study that explained variation in myocardial tissue characteristics (including $T_{1}$, $\mathrm{T}_{2}$, and ECV) using multivariate regression analysis with cardiovascular risk factor-related predictors. BMI showed a significant association with native $\mathrm{T}_{1}$ values, while previous studies showed similar $\mathrm{T}_{1}$ values in both overweight (aged 41 \pm 13 years) and obese subjects (aged $32 \pm 7$ years) relative to normal weights $(22,42)$. Comparable to our results, T2D populations had similar $\mathrm{T}_{1}$ values relative to controls (21). Previous studies reported increased $\mathrm{T}_{1}$ values in hypertensive subjects with LVH (15). We found no such association, which is probably related to the relatively small LV mass increase in our hypertensives.

Current results indicate that increased BMI and blood pressure are associated with reduced ECV, suggesting hypertrophy of myocytes similar as seen in athletes (43). Conversely, ECV is often increased in non-ischemic cardiomyopathies (14). ECV could therefore potentially discriminate adaptations associated with overweight, obesity, or hypertension from early pathology, such as previously suggested to distinguish the athlete's heart from HCM $(20,44)$. The positive association between $\mathrm{HbA} 1 \mathrm{c}$ and ECV was in agreement with findings in subjects with T2D (21). Increased ECV is linked to heart failure (45), underlining the importance of its early recognition.

Heart rate was the most significant negatively associated predictor of $\mathrm{T}_{2}$ values. This can be explained by the nature of the $\mathrm{T}_{2}$-prepared SSFP sequence, which can produce incomplete $\mathrm{T}_{1}$ relaxation during increased HRs, influencing $\mathrm{T}_{2}$ values (46). Individuals with cardiovascular risk factors often have increased HRs, as confirmed in the current study (31). Using standard $\mathrm{T}_{2}$-prepared SSFP sequences could therefore result in underestimation of true $\mathrm{T}_{2}$ values in these populations, which needs to be taken into consideration (28).

Increased SBP was the only other independently associated predictor of (lower) $\mathrm{T}_{2}$ values. Our findings confirm similar $\mathrm{T}_{2}$ values reported for normal-weight and overweight subgroups (age $41 \pm 13$ years) (42), however, they are in contrast with studies reporting higher $\mathrm{T}_{2}$ values in T2D populations (aged 56 \pm 12 years) and hypertensives with $\mathrm{LVH}$ (aged $54 \pm 16$ years) $(24,25)$. Most likely, in the latter group, higher $T_{2}$ values are caused by the used scanning techniques, FLASH, which is not susceptible to HR effects. Discrepancies might be explained by longer exposure to risk factors causing $\mathrm{T}_{2}$ alterations similar to those found in non-ischemic cardiomyopathies (16).

\section{Limitations}

Firstly, we did not measure the metabolic risk factors triglyceride and cholesterol (47), therefore their impact on cardiac outcomes was not tested. Nevertheless, as previously reported in mature populations, these risk factors have substantially less impact on the heart than the risk factors included in our study (1012). Secondly, in this young asymptomatic population, we 
could not link the demonstrated subclinical cardiac alterations with long-term adverse events due to the cross-sectional study design. Longitudinal studies on young high-risk populations may provide insights on this matter. Thirdly, our prospectively included young adult population was relatively small compared to mature populations in previous studies using a retrospective study design (10-12). Nevertheless, our population size allowed for appropriate multivariate linear regression (48).

\section{CONCLUSION}

In summary, we showed in an asymptomatic young adult population that sedentary lifestyle-related risk factors are associated with subclinical cardiac alterations on MRI, and this needs to be considered in clinical decision-making. These findings are also comparable to studies in more mature populations, which already demonstrated that subclinical cardiac alterations are associated with long-term adverse cardiac events. If current trends in risk factor prevalence keep rising, this may cause additional cardiovascular disease burden, especially in Westernized countries.

\section{DATA AVAILABILITY STATEMENT}

The original contributions presented in the study are included in the article Supplementary Material, further inquiries can be directed to the corresponding author.

\section{REFERENCES}

1. Arnett DK, Blumenthal RS, Albert MA, Buroker AB, Goldberger ZD, Hahn EJ, et al. 2019 ACC/AHA Guideline on the Primary Prevention of Cardiovascular Disease: A Report of the American College of Cardiology/American Heart Association Task Force on Clinical Practice Guidelines. Circulation. (2019) 140:e596-646. doi: 10.1161/CIR.0000000000000678

2. Wong MCS, Huang J, Wang J, Chan PSF, Lok V, Chen X. et al. Global, regional and time-trend prevalence of central obesity: a systematic review and meta-analysis of 132 million subjects. Eur J Epidemiol. (2020) 35:673-83. doi: 10.1007/s10654-020-00650-3

3. Thompson P, Logan I, Tomson C, Sheerin N, Ellam T. Obesity, Sex, Race, and Early onset hypertension: implications for a refined investigation strategy. Hypertension. (2020) 76:859-65. doi: 10.1161/HYPERTENSIONAHA.120.15557

4. Wilmot EG, Leggate M, Khan JN, Yates T, Gorely T, Bodicoat DH, et al. Type 2 diabetes mellitus and obesity in young adults: The extreme phenotype with early cardiovascular dysfunction. Diabet Med. (2014) 31:7948. doi: 10.1111/dme.12431

5. Andersson C, Vasan RS. Epidemiology of cardiovascular disease in young individuals. Nat Rev Cardiol. (2018) 15:230-40. doi: $10.1038 /$ nrcardio. 2017.154

6. Sen-Chowdhry S, McKenna WJ. Sudden death from genetic and acquired cardiomyopathies. Circulation. (2012) 125:1563-76. doi: 10.1161/CIRCULATIONAHA.111.025528

7. McDonagh TA, Metra M, Adamo M, Gardner RS, Baumbach A, Böhm M, et al. 2021 ESC Guidelines for the diagnosis and treatment of acute and chronic heart failure. Eur Heart J. (2021) 42:3599-726. doi: 10.1093/eurheartj/ ehab368

\section{ETHICS STATEMENT}

The studies involving human participants were reviewed and approved by Medical Ethics Committee of the University Medical Center Groningen (no. 2016/476). The patients/participants provided their written informed consent to participate in this study.

\section{AUTHOR CONTRIBUTIONS}

$\mathrm{VD}, \mathrm{RD}, \mathrm{BV}$, and NP conceptualized the study. GS, MB, KH-O, and NP drafted the manuscript. GS, MB, RB, and NP contributed in data acquisition. GS and NP interpreted the data. RS, RD, and NP supervised the project. RD, RB, and NP were responsible for resources. RS, VD, CN, DS, and BV were responsible for review and editing. All authors approved the submitted manuscript.

\section{FUNDING}

This work was supported by the Dutch Heart Association (2016T042).

\section{SUPPLEMENTARY MATERIAL}

The Supplementary Material for this article can be found online at: https://www.frontiersin.org/articles/10.3389/fcvm. 2022.840790/full\#supplementary-material

8. Bluemke DA. Cardiac MRI of nonischemic cardiomyopathy. AJR Am J Roentgenol. (2010) 195:935-40. doi: 10.2214/AJR.10. 4222

9. Pinto YM, Elliott PM, Arbustini E, Adler Y, Anastasakis A, Böhm M, et al. Proposal for a revised definition of dilated cardiomyopathy, hypokinetic non-dilated cardiomyopathy, and its implications for clinical practice: a position statement of the ESC working group on myocardial and pericardial diseases. Eur Heart J. (2016) 37:1850-8. doi: 10.1093/eurheartj/ ehv727

10. Petersen SE, Sanghvi MM, Aung N, Cooper JA, Paiva JM, Zemrak F, et al. The impact of cardiovascular risk factors on cardiac structure and function: Insights from the UK Biobank imaging enhancement study. PLoS ONE. (2017) 12:1-14. doi: 10.1371/journal.pone.01 85114

11. Heckbert SR, Post W, Pearson GDN, Arnett DK, Gomes AS, Jerosch-Herold $\mathrm{M}$, et al. Traditional cardiovascular risk factors in relation to left ventricular mass, volume, and systolic function by cardiac magnetic resonance imaging. The multiethnic study of atherosclerosis. J Am Coll Cardiol. (2006) 48:228592. doi: 10.1016/j.jacc.2006.03.072

12. Nham E, Kim SM, Lee SC, Chang SA, Sung J, Cho SJ, et al. Association of cardiovascular disease risk factors with left ventricular mass, biventricular function, and the presence of silent myocardial infarction on cardiac MRI in an asymptomatic population. Int J Cardiovasc Imaging. (2016) 32:173-81. doi: 10.1007/s10554-016-0885-1

13. Chahal H, Johnson C, Tandri H, Jain A, Hundley WG, Barr RG, et al. Relation of cardiovascular risk factors to right ventricular structure and function as determined by magnetic resonance imaging (Results from the Multi-Ethnic Study of Atherosclerosis). Am J Cardiol. (2010) 106:110-6. doi: 10.1016/j.amjcard.2010.02.022 
14. Messroghli DR, Moon JC, Ferreira VM, Grosse-Wortmann L, He T, Kellman $\mathrm{P}$, et al. Clinical recommendations for cardiovascular magnetic resonance mapping of $\mathrm{T} 1, \mathrm{~T} 2, \mathrm{~T} 2 *$ and extracellular volume: a consensus statement by the Society for Cardiovascular Magnetic Resonance (SCMR) endorsed by the European Association for Cardiovascular Imaging (EACVI). J Cardiovasc Magn Reson. (2017) 19:1-24. doi: 10.1186/s12968-0170389-8

15. van den Boomen $M$, Slart RHJA, Hulleman EV, Dierckx RAJO, Velthuis BK, van der Harst $P$, et al. Native T1 reference values for nonischemic cardiomyopathies and populations with increased cardiovascular risk: a systematic review and meta-analysis. $J$ Magn Reson Imaging. (2018) 47:891-912. doi: 10.1002/jmri. 25885

16. Snel GJH, van den Boomen M, Hernandez LM, Nguyen CT, Sosnovik $\mathrm{DE}$, Velthuis BK, et al. Cardiovascular magnetic resonance native T2 and T2* quantitative values for cardiomyopathies and heart transplantations: a systematic review and meta-analysis. J Cardiovasc Magn Reson. (2020) 22:34. doi: 10.1186/s12968-020-00627-x

17. Scully PR, Bastarrika G, Moon JC, Treibel TA. Myocardial extracellular volume quantification by cardiovascular magnetic resonance and computed tomography. Curr Cardiol Rep. (2018) 20:1-11. doi: 10.1007/s11886-018-0961-3

18. Gastl M, Lachmann V, Christidi A, Janzarik N, Veulemans V, Haberkorn S, et al. Cardiac magnetic resonance T2 mapping and feature tracking in athlete's heart and HCM. Eur Radiol. (2021) 31:2768-77. doi: 10.1007/s00330-020-07289-4

19. Tadic M, Cuspidi C, Plein S, Milivojevic IG, Wang DW, Grassi G, et al. Comprehensive assessment of hypertensive heart disease: cardiac magnetic resonance in focus. Heart Fail Rev. (2020) 26:1383-90. doi: 10.1007/s10741-020-09943-x

20. Hinojar R, Varma N, Child N, Goodman B, Jabbour A, Yu C, et al. T1 Mapping in Discrimination of Hypertrophic Phenotypes: Hypertensive Heart Disease and Hypertrophic Cardiomyopathy: Findings From the International T1 Multicenter Cardiovascular Magnetic Resonance Study. Circ Cardiovasc Imaging. (2015) 8:e003285. doi: 10.1161/CIRCIMAGING.115. 003285

21. Tadic M, Cuspidi C, Calicchio F, Grassi G, Mancia G. Diabetic cardiomyopathy: How can cardiac magnetic resonance help? Acta Diabetol. (2020) 57:1027-34. doi: 10.1007/s00592-02001528-2

22. Khan JN, Wilmot EG, Leggate $M$, Singh A, Yates $T$, Nimmo $M$, et al. Subclinical diastolic dysfunction in young adults with Type 2 diabetes mellitus: a multiparametric contrast-enhanced cardiovascular magnetic resonance pilot study assessing potential mechanisms. Eur Heart J Cardiovasc Imaging. (2014) 15:1263-9. doi: 10.1093/ehjci/ jeu121

23. Homsi R, Yuecel S, Schlesinger-Irsch U, Meier-Schroers M, Kuetting D, Luetkens J, et al. Epicardial fat, left ventricular strain, and T1-relaxation times in obese individuals with a normal ejection fraction. Acta radiol. (2019) 60:1251-7. doi: 10.1177/0284185119826549

24. Arcari L, Hinojar R, Engel J, Freiwald T, Platschek S, Zainal H, et al. Native $\mathrm{T} 1$ and $\mathrm{T} 2$ provide distinctive signatures in hypertrophic cardiac conditions - Comparison of uremic, hypertensive and hypertrophic cardiomyopathy. Int J Cardiol. (2020) 306:102-8. doi: 10.1016/j.ijcard.2020. 03.002

25. Jiang L, Wang J, Liu X, Li ZL, Xia C, Xie L, et al. The combined effects of cardiac geometry, microcirculation, and tissue characteristics on cardiac systolic and diastolic function in subclinical diabetes mellitus-related cardiomyopathy. Int J Cardiol. (2020) 320:112-8. doi: 10.1016/j.ijcard.2020.07.013

26. Prakken NH, Velthuis BK, Teske AJ, Mosterd A, Mali WP, Cramer MJ. Cardiac MRI reference values for athletes and nonathletes corrected for body surface area, training hours/week and sex. Eur J Cardiovasc Prev Rehabil. (2010) 17:198-203. doi: 10.1097/HJR.0b013e3283347fdb

27. Williams B, Mancia G, Spiering W, Rosei EA, Azizi M, Burnier M, et al. 2018 practice guidelines for the management of arterial hypertension of the European society of cardiology and the European society of hypertension
ESC/ESH task force for the management of arterial hypertension. J Hypertens. (2018) 39:3021-104. doi: 10.1097/HJH.0000000000001961

28. Kramer CM, Barkhausen J, Flamm SD, Kim RJ, Nagel E. Standardized cardiovascular magnetic resonance (CMR) protocols 2020 update. J Cardiovasc Magn Reson. (2020) 22:1-18. doi: 10.1186/s12968-02000607-1

29. Snel GJH, Poort S, Velthuis BK, Deursen VM. Van, Nguyen CT, Sosnovik $\mathrm{D}$, et al. Balancing speed and accuracy in cardiac magnetic resonance function post-processing : comparing 2 levels of automation in 3 vendors to manual assessment. Diagnostics. (2021) 11:1758. doi: 10.3390/diagnostics11 101758

30. Mordi I, Carrick D, Bezerra H, Tzemos N. T1 and T2 mapping for early diagnosis of dilated non-ischaemic cardiomyopathy in middle-aged patients and differentiation from normal physiological adaptation. Eur Heart J Cardiovasc Imaging. (2016) 17:797-803. doi: 10.1093/ehjci/jev216

31. Tadic M, Cuspidi C, Grassi G. Heart rate as a predictor of cardiovascular risk. Eur J Clin Invest. (2018) 48:1-11. doi: 10.1111/eci.12892

32. Murray K, Conner MM. Methods to quantify variable importance: implications for the analysis of noisy ecological data. Ecology. (2009) 90:34855. doi: 10.1890/07-1929.1

33. Vatcheva KP, Lee M, McCormick JB, Rahbar MH. Multicollinearity in regression analyses conducted in epidemiologic studies. Epidemiology. (2016) 6:227. doi: 10.4172/2161-1165.1000227

34. Urbina EM, Mendizábal B, Becker RC, Daniels SR, Falkner BE, Hamdani $\mathrm{G}$, et al. Association of blood pressure level with left ventricular mass in adolescents: SHIP AHOY. Hypertension. (2019) 74:590-6. doi: 10.1161/HYPERTENSIONAHA.119.13027

35. Palmieri V, Bella JN, Arnett DK, Liu JE, Oberman A, Schuck MY, et al. Effect of type 2 diabetes mellitus on left ventricular geometry and systolic function in hypertensive subjects hypertension genetic epidemiology network (HyperGEN) study. Circulation. (2001) 103:102-7. doi: 10.1161/01.CIR.103.1.102

36. De Marco M, De Simone G, Roman MJ, Chinali M, Lee ET, Calhoun D, et al. Cardiac geometry and function in diabetic or prediabetic adolescents and young adults: the strong heart study. Diabetes Care. (2011) 34:2300-5. doi: $10.2337 / \mathrm{dc} 11-0191$

37. Bluemke DA, Kronmal RA, Lima JAC, Liu K, Olson J, Burke GL, et al. The Relationship of Left Ventricular Mass and Geometry to Incident Cardiovascular Events: the MESA study. J Am Coll Cardiol. (2008) 52:214855. doi: 10.1016/j.jacc.2008.09.014

38. Foppa M, Arora G, Gona P, Ashrafi A, Salton CJ, Yeon SB, et al. Right ventricular volumes and systolic function by cardiac magnetic resonance and the impact of sex, age, and obesity in a longitudinally followed cohort free of pulmonary and cardiovascular disease: the Framingham Heart Study. Circ Cardiovasc Imaging. (2016) 9:e003810. doi: 10.1161/CIRCIMAGING.115.003810

39. Després JP. Body fat distribution and risk of cardiovascular disease: an update. Circulation. (2012) 126:1301-13. doi: 10.1161/CIRCULATIONAHA.111.067264

40. Neeland IJ, Gupta S, Ayers CR, Turer AT, Rame EJ, Das SR, et al. Relation of Regional Fat Distribution to Left Ventricular Structure and Function. Circ Cardiovasc Imaging. (2013) 6:800-7. doi: 10.1161/CIRCIMAGING.113.000532

41. Jensen MT, Fung K, Aung N, Sanghvi MM, Chadalavada S, Paiva JM, et al. Changes in cardiac morphology and function in individuals with diabetes mellitus: the UK biobank cardiovascular magnetic resonance substudy. Circ Cardiovasc Imaging. (2019) 12:e009476. doi: 10.1161/CIRCIMAGING.119.009476

42. Granitz M, Motloch LJ, Granitz C, Meissnitzer M, Hitzl W, Hergan K et al. Comparison of native myocardial $\mathrm{T} 1$ and $\mathrm{T} 2$ mapping at $15 \mathrm{~T}$ and $3 \mathrm{~T}$ in healthy volunteers: Reference values and clinical implications. Wien Klin Wochenschr. (2019) 131:143-55. doi: 10.1007/s00508-0181411-3

43. McDiarmid AK, Swoboda PP, Erhayiem B, Lancaster RE, Lyall GK, Broadbent DA, et al. Athletic cardiac adaptation in males is a consequence of elevated myocyte mass. Circ Cardiovasc Imaging. (2016) 9:1-8. doi: 10.1161/CIRCIMAGING.115.003579 
44. Swoboda PP, McDiarmid AK, Erhayiem B, Broadbent DA, Dobson LE, Garg P, et al. Assessing Myocardial Extracellular Volume by T1 Mapping to Distinguish Hypertrophic Cardiomyopathy from Athlete's Heart. J Am Coll Cardiol. (2016) 67:2189-90. doi: 10.1016/j.jacc.2016. 02.054

45. Wong TC, Piehler KM, Kang IA, Kadakkal A, Kellman P, Schwartzman DS, et al. Myocardial extracellular volume fraction quantified by cardiovascular magnetic resonance is increased in diabetes and associated with mortality and incident heart failure admission. Eur Heart J. (2014) 35:657-64. doi: 10.1093/eurheartj/eht193

46. Von Knobelsdorff-Brenkenhoff F, Prothmann M, Dieringer MA, Wassmuth R, Greiser A, Schwenke C, et al. Myocardial T1 and T2 mapping at 3 T: Reference values, influencing factors and implications. J Cardiovasc Magn Reson. (2013) 15:53. doi: 10.1186/1532-429X-15-53

47. Saklayen M. The global epidemic of the metabolic syndrome. Curr Hypertens Rep. (2018) 20:1-8. doi: 10.1007/s11906-018-0812-Z

48. Jenkins DG, Quintana-Ascencio PF. A solution to minimum sample size for regressions. PLoS ONE. (2020) 15:1-15. doi: 10.1371/journal.pone.022 9345
Conflict of Interest: The authors declare that the research was conducted in the absence of any commercial or financial relationships that could be construed as a potential conflict of interest.

Publisher's Note: All claims expressed in this article are solely those of the authors and do not necessarily represent those of their affiliated organizations, or those of the publisher, the editors and the reviewers. Any product that may be evaluated in this article, or claim that may be made by its manufacturer, is not guaranteed or endorsed by the publisher.

Copyright (c) 2022 Snel, van den Boomen, Hurtado-Ortiz, Slart, van Deursen, Nguyen, Sosnovik, Dierckx, Velthuis, Borra and Prakken. This is an open-access article distributed under the terms of the Creative Commons Attribution License (CC $B Y)$. The use, distribution or reproduction in other forums is permitted, provided the original author(s) and the copyright owner(s) are credited and that the original publication in this journal is cited, in accordance with accepted academic practice. No use, distribution or reproduction is permitted which does not comply with these terms. 